\title{
Proliferation, angiogenesis and differentiation related markers in compact and follicular-compact thyroid carcinomas in dogs
}

\author{
P. Pessina ${ }^{1, *}$, V.A. Castillo ${ }^{2}$, D. César ${ }^{3}$, I. Sartore ${ }^{1}$ and A. Meikle ${ }^{1}$ \\ ${ }^{1}$ Laboratorio de Técnicas Nucleares, Facultad de Veterinaria, Universidad de la República, Lasplaces 1550, \\ Montevideo, Uruguay \\ ${ }^{2}$ Cat. Clin. Méd. Peq. An. and U. Endocrinología, Escuela Medicina Veterinaria, Facultad de Ciencias Veterinarias, \\ Universidad de Buenos Aires. Av. Chorroarín 280, C. Autónoma de Buenos Aires, Argentina \\ ${ }^{3}$ Instituto Plan Agropecuario, Br. Artigas 3802, Montevideo, Uruguay
}

\begin{abstract}
Immunohistochemical markers (IGF-1, IGF-1R, VEGF, FGF-2, RAR $\alpha$ and RXR) were evaluated in healthy canine thyroid glands $(\mathrm{n}=8)$ and in follicular-compact $(\mathrm{n}=8)$ and compact thyroid carcinomas $(\mathrm{n}=8)$. IGF-1, IGF-1R and VEGF expression was higher in fibroblasts and endothelial cells of compact carcinoma than in healthy glands $(P<$ 0.05). Compared to follicular-compact carcinoma, compact carcinoma had higher IGF-1R expression in fibroblasts, and higher FGF-2 expression in endothelial cells $(P<0.05)$. RAR $\alpha$ expression was higher in endothelial cells of compact carcinoma than in those of other groups $(P<0.05)$. The upregulation of these proliferation- and angiogenesisrelated factors in endothelial cells and/or fibroblasts and not in follicular cells of compact carcinoma compared to healthy glands supports the relevance of stromal cells in cancer progression.
\end{abstract}

Keywords: Canine, Histology, Immunohistochemistry, Thyroid carcinoma.

\section{Introduction}

Similar to humans, thyroid cancer is the most common endocrine malignancy in dogs and the leading cause of death among endocrine cancers (Barber, 2007). Ninety percent of canine thyroid tumours are carcinomas, and $16-38 \%$, and even up to $60 \%$, of patients show evidence of metastasis at the time of diagnosis (Wucherer and Wilke, 2010; Campos et al., 2012). In dogs, the most frequent thyroid tumour types are derived from follicular epithelial cells, and the most common histological patterns are follicular, follicularcompact and compact (Ramos-Vara et al., 2002; Nadeau and Kitchell, 2011). Most canine thyroid tumours are well to moderately differentiated (Klein et al., 1995). Although surgery is often successful in the early stages of the disease, unsatisfactory results are obtained in advanced tumours. Therefore, a better understanding of the molecular mechanisms and intracellular networks associated with oncogenesis may help discover new therapeutic options for these malignancies (Malaguarnera et al., 2012).

Alterations in the expression of growth factors such as insulin-like growth factor (IGF)-1, vascular endothelial growth factor (VEGF) and fibroblast growth factor (FGF)-2, and their receptors, play a role in the progression of thyroid cancer in humans and dogs (de Araujo-Filho et al., 2009; Redler et al., 2013; Campos et al., 2014). The activation of the IGF system is associated with the pathogenesis of a variety of human neoplasias because of the mitogenic and anti-apoptotic properties of its cognate receptor (Vella et al., 2001; Ciampolillo et al., 2007). IGF-1, a potent mitogen in many cell types, promotes the progression of mitosis via the induction of DNA synthesis and has long-term effects on cell proliferation, differentiation and apoptosis (Jones and Clemmons, 1995). Experimental evidence suggests that IGF-1 plays a significant role in the transformation, infiltrative growth and metastasis of tumour cells (LeRoith and Roberts, 2003; Liu and Brown, 2011). Moreover, IGF-1/IGF-1R are overexpressed in some types of thyroid carcinomas in humans, and it is correlated with poor prognosis (Liu et al., 2013).

In the absence of vascular support, tumours may become necrotic or even apoptotic (Holmgren et al., 1995). New growth in the vascular network is important because the proliferation, as well as metastatic spread, of cancer cells depends on an adequate supply of oxygen and nutrients, and the removal of waste products (Nishida et al., 2006). In addition, tumour angiogenesis is controlled by positive and negative modulators produced by neoplastic, stromal and tumour-infiltrating cells (Carmeliet and Jain, 2000). Studies showed that vascular tumour markers, such as VEGF expression, are increased in association with poor outcome in some canine compact tumours (Restucci et al., 2003). VEGF is essential for the growth of new vessels under normal physiological 
conditions as well as in tumour cells, and it plays an important role in the development of distant metastases (Lin and Chao, 2005). In dogs, VEGF is expressed at higher levels in endothelial cells of canine thyroid glands with carcinoma than in those of healthy glands, which is consistent with the higher number of blood vessels and cell density (Campos et al., 2014; Pessina et al., 2014). FGF-2 is also implicated in abnormal human thyroid growth, both as a potential follicular cell mitogen and as a stimulator of thyroid endothelial cell growth. Reports on FGF-2 levels in thyroid carcinoma are contradictory (Kondo et al., 2007), and its expression may depend on the degree of differentiation (Boelaert et al., 2003).

Differentiating factors redirect cells toward their normal phenotype and may reverse or suppress carcinogenesis (Miller, 1998). Retinoids are natural or synthetic derivatives of vitamin A that modulate cell growth, differentiation and apoptosis (de Mello Souza et al., 2014). In dogs, retinoids are used to treat various types of cancer such as cutaneous lymphoma, mast cell tumours and corticotroph adenoma of the pituitary (White et al., 1993; Miyajima et al., 2006; Ohashi et al., 2006; Castillo et al., 2006; Castillo and Gallelli, 2010), and recently in thyroid carcinoma (Castillo et al., 2016). The action of retinoic acid is mediated by retinoic acid receptors (RARs) and the retinoid X receptors (RXRs) (Kasimanickam et al., 2013). Both receptors are expressed in cutaneous lymphoma in dogs (de Mello Souza et al., 2010); however, their expression in the thyroid gland has not been described to date.

Based on evidence showing that primary tumours are composed of a multitude of stromal cell types in addition to cancerous cells (Tlsty and Coussens, 2006), we investigated different markers (VEGF, FGF-2, IGF-1, IGF-1R, RAR $\alpha$ and RXR) in compact and follicular-compact canine thyroid carcinomas.

\section{Experimental design}

\section{Materials and Methods}

All experiments were performed in accordance with the regulations of the Animal Experimentation Committees of the Faculty of Veterinary Medicine, Universidad de la República, Uruguay, and the Faculty of Veterinary Sciences, University of Buenos Aires, Argentina.

\section{Tissue samples}

Tissue samples were collected from the Endocrinology Unit, Faculty of Veterinary Medicine, University of Buenos Aires, Argentina, and the Veterinary Hospital, Faculty of Veterinary Medicine, University of Uruguay. Canine tissue samples were selected as follows: normal thyroid tissues were obtained from dogs that had been euthanised for reasons unrelated to thyroid disease (traumatized or aggressive patients) and had histopathologically normal thyroid glands (healthy group, $\mathrm{n}=8$ ); thyroid follicular carcinomas were obtained postsurgically (carcinoma group, $\mathrm{n}=16$ ). Tumours were classified according to the World Health Organization (WHO).

Haematoxylin and eosin stained specimens were classified into two categories, namely, follicularcompact carcinoma $(\mathrm{n}=8)$ and compact carcinoma (n $=8$ ), according to the predominant histological pattern and following established criteria for thyroid neoplasms. Classification of thyroid tumours according to thyroglobulin and calcitonin immunohistochemistry was performed as previously described (Patnaik and Lieberman, 1991); all tumours included in this study were positive for the former and negative for the latter. All samples were processed in the Laboratory of Nuclear Techniques, Faculty of Veterinary Medicine, University of Uruguay.

\section{Immunohistochemistry}

Samples were fixed in $4 \%$ paraformaldehyde in phosphate-buffered saline (PBS) and embedded in paraffin for immunohistochemistry. Immunoreactivity against VEGF, FGF-2, IGF-1, IGF-1R, RAR $\alpha$, RXR, thyroglobulin and calcitonin was assessed in transverse $5 \mu \mathrm{m}$ sections of healthy thyroid gland and thyroid carcinoma specimens using the avidin-biotin peroxidase immunohistochemical technique, as previously described (Pessina et al., 2014). Paraffin embedded tissue sections were de-waxed and rehydrated, and antigen retrieval was performed. Sections were pretreated in a microwave oven at $900 \mathrm{~W}$ in 0.01 $\mathrm{M}$ sodium citrate buffer ( $\mathrm{pH}$ 6.0) for 9 min, and then allowed to cool for $20 \mathrm{~min}$. After washing in buffer (0.01 M PBS, pH 7.4), non-specific endogenous peroxidase activity was blocked by exposure to $3 \%$ hydrogen peroxide in methanol for $10 \mathrm{~min}$ at room temperature. After another wash in buffer $(10 \mathrm{~min})$, sections were blocked in normal horse or goat serum diluted in PBS (Vectastain, Vector Laboratories, Burlingame, CA) for $30 \mathrm{~min}$ at room temperature in a humidified chamber. Sections were incubated with the primary antibodies for one hour a humidity chamber at room temperature (Table 1).

Negative control immunolabeling was performed for each receptor by replacing the primary antibody with non-immune IgG (Santa Cruz Biotechnology), diluted 1:100 in PBS. After primary antibody binding, sections were incubated with a biotinylated secondary antibody (horse anti-mouse or goat anti-rabbit IgG; Vector Laboratories), diluted 1:200 in normal horse (thyroglobulin and IGF-1) or goat serum (the remaining antibodies). A Vectastain ABC kit (Vector Laboratories) was used for the detection of all proteins. The site of the bound enzyme was visualised by 3, 3'diaminobenzidine (DAB), a chromogen that produces a brown insoluble precipitate when incubated with the enzyme, in $\mathrm{H}_{2} \mathrm{O}_{2}$ using a DAB kit (Vector Laboratories). 
Table 1. Primary antibodies used for immunohistochemistry.

\begin{tabular}{|c|c|c|c|}
\hline Antibody & $\begin{array}{l}\text { Antibody } \\
\text { Name }\end{array}$ & Antibody Type & Dilution \\
\hline Calcitonin & A $0576^{\mathrm{a}}$ & Rabbit polyclonal & $1: 1000$ \\
\hline Thyroglobulin & sc-365997b & Mouse monoclonal & $1: 75$ \\
\hline VEGF & $\mathrm{sc}-152^{\mathrm{b}}$ & Rabbit polyclonal & $1: 200$ \\
\hline FGF-2 & sc-79 ${ }^{b}$ & Rabbit polyclonal & $1: 200$ \\
\hline IGF-1 & sc- $1422^{b}$ & Goat polyclonal & $1: 50$ \\
\hline IGF-1R & ab $5497^{c}$ & Rabbit polyclonal & $1: 50$ \\
\hline RAR $\alpha$ & $\mathrm{sc}-551^{\mathrm{b}}$ & Rabbit polyclonal & $1: 100$ \\
\hline RXR & $\mathrm{sc}-831^{\mathrm{b}}$ & Rabbit polyclonal & $1: 100$ \\
\hline
\end{tabular}

${ }^{\mathrm{a} D a k o, ~ G l o s t r u p, ~ D e n m a r k . ~}{ }^{\mathrm{b}}$ Santa Cruz Biotechnology, Inc, Dallas, TX. ${ }^{\mathrm{c} A b c a m}$, Cambridge, USA.

Sections were counterstained with haematoxylin and dehydrated before mounting with Entellan ${ }^{\circledR}$ (Merck, Darmstadt, Germany). For each protein, all samples were analysed using same immunohistochemical assay. Image analysis

Cell density (number of cells/field) and number of blood vessels were counted in 15 images captured from each histological section at $40 \times$ magnification. Three cell types, namely, follicular cells, endothelial cells and fibroblasts, were evaluated in the same images. Immunolabeling of the nucleus or cytoplasm was scored as negative $(-)$, faint $(+)$, moderate $(++)$ or intense $(+++)$ by two independent observers who were blinded to the treatment groups (Pessina et al., 2014). The average labeling intensity was calculated as $(1 \times$ $\mathrm{n} 1)+(2 \times \mathrm{n} 2)+(3 \times \mathrm{n} 3)$, where $\mathrm{n}$ is the number of cells in each field exhibiting faint (n1), moderate (n2) and intense (n3) labeling (Boos et al., 1996). The average of the abovementioned variables in the 15 images captured from each histological section was used for statistical analysis.

\section{Statistical analysis}

Univariate analyses were performed on all variables to identify outliers and to verify the normality of residuals. Antigen immunolabeling intensity was evaluated by analysis of variance using a mixed model (Statistical Analysis System, SAS Institute, Cary, NC). The statistical model used to assess labeling intensity included observer effects, animal group (healthy thyroid gland, follicular-compact carcinoma and compact carcinoma), and cell type (follicular cells, fibroblasts and endothelial cells) and their interactions. Cell density was analysed by PROC MIXED (SAS, V9.0) with the animal group included in the model. Since blood vessels were not detected in the images of most healthy animals (7/8), the number of blood vessels was analysed by PROC GENMOD using a binomial distribution (presence or not of vessels) including the animal group in the model. Data are presented as the least square mean \pm pooled S.E.M. The level of significance was set at $\mathrm{P}<0.05$.

\section{Results}

\section{Number of blood vessels and cell density}

Cell density was higher in compact carcinomas and follicular-compact carcinomas than in healthy glands (cells per field: $288 \pm 24,221 \pm 24$ and $142 \pm 24$, respectively, $P<0.03$ ). Moreover, the number of cells per field tended to be higher in compact carcinomas than in follicular-compact carcinomas $(P=0.06)$. A significant group effect was observed regarding the number of blood vessels $(P=0.007)$, with a greater number of blood vessels observed in thyroid follicularcompact carcinomas than in healthy thyroid tissue $(P=$ $0.01)$, and in compact carcinomas than in the healthy group $(P<0.1)$, although the latter did not reach statistical significance.

\section{Protein localisation}

Positive immunolabeling for IGF-1, IGF-1R, VEGF, FGF-2, RAR $\alpha$ and RXR was observed in the cytoplasm in all cell types analysed (Figs. 1, 2 and 3). Five carcinoma samples (two compact and three follicularcompact) had positive labeling for nuclear IGF-1R, although the percentage of positive cells was too low for statistical analysis. Nuclear RAR $\alpha$ and RXR labeling was also detected in follicular cells in eight (three compact and five follicular-compact) and two (one compact and one follicular-compact) carcinoma samples. For all assays, no immunolabeling was observed when the primary antibody was replaced by non-specific $\mathrm{IgG}$.

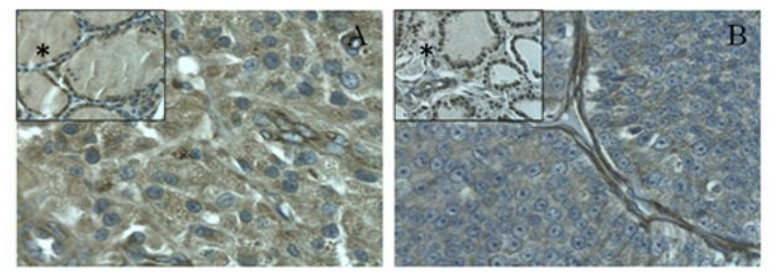

Fig. 1. Immunoreactivity of insulin-like growth factor-1 (IGF-1, A) and insulin-like growth factor-1 receptor (IGF-1R, B) in thyroid compact carcinoma. Cytoplasmic labeling in follicular cells is shown. The asterisk (*) shows expression in healthy thyroid tissue. All images were captured at a magnification of $400 \times$.

Overall, IGF-1 and IGF-1R labeling intensities were higher in compact carcinoma than in healthy thyroid tissues, although the differences did not reach statistical significance ( $P=0.09$ and $P=0.07$, respectively). IGF1 and IGF-1R expression was higher in fibroblasts and endothelial cells of compact carcinomas than in those of healthy thyroid tissues $(P<0.05)$, whereas no differences were observed for follicular cells (Fig. 4A and $\mathrm{B}$ ).

No differences were observed between compact and follicular-compact carcinomas, except in fibroblasts, where compact carcinomas showed higher IGF-1R labeling intensity $(P<0.05)$. 


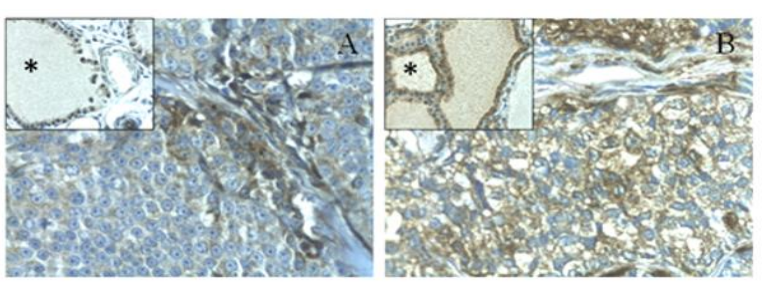

Fig. 2. Vascular endothelial growth factor (VEGF, A) and fibroblast growth factor-2 (FGF-2, B) cytoplasmic labeling in thyroid compact carcinoma. The asterisk (*) shows expression in healthy thyroid tissues. All images were captured at a magnification of $400 \times$.

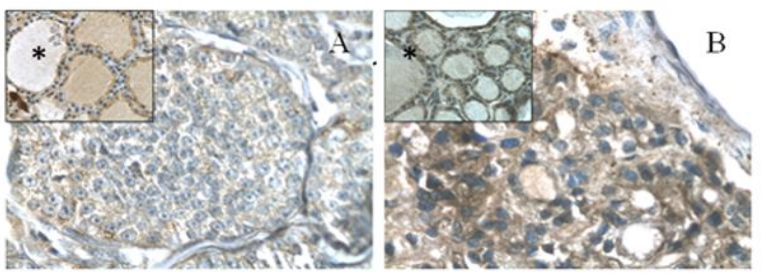

Fig. 3. Cytoplasmic immunolabeling of retinoic acid receptor alpha $(\mathrm{RAR} \alpha, \mathrm{A})$ and retinoid $\mathrm{X}$ receptor $(\mathrm{RXR}, \mathrm{B})$ in thyroid compact carcinoma. All images were captured at a magnification of $400 \times$.

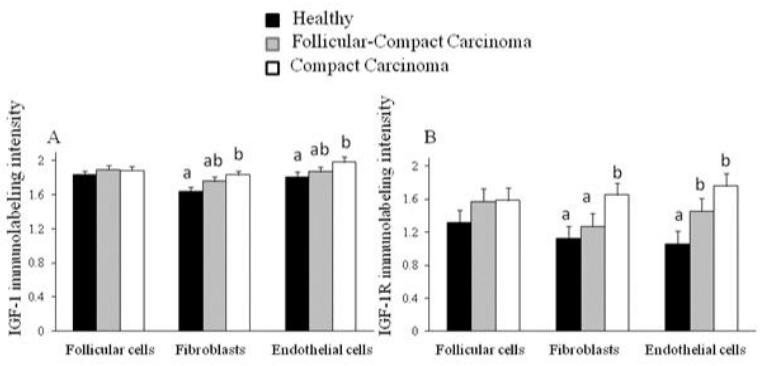

Fig. 4. Immunolabeling intensity of insulin-like growth factor-1 (IGF-1, A) and insulin-like growth factor-1 receptor (IGF-1R, B). Data are expressed as the least square mean \pm pooled S.E.M. Different letters within the same cell type indicate differences, $\mathrm{P}<0.05$.

Overall, VEGF expression was higher in compact carcinomas than in healthy thyroid tissues $(P<0.05)$ and follicular-compact carcinomas $(P<0.1)$. Stronger labeling for VEGF was detected in fibroblasts and endothelial cells of compact carcinomas than in those of normal thyroid tissues $(P<0.05)$ (Fig. 5A). No differences in FGF-2 labeling intensity were detected in follicular cells and fibroblasts, whereas endothelial cells of compact carcinomas showed higher FGF-2 immunolabeling than the other two groups $(P<0.05)$ (Fig. 5B).

In endothelial cells, RAR $\alpha$ immunolabeling was higher in compact carcinomas than in the other two groups $(P$ $<0.01)$. An altered pattern of RAR $\alpha$ expression in different cells types according to group was observed; a stronger labeling in follicular cells than fibroblasts and endothelial cells of healthy glands was found $(P<$
0.05), whereas no differences according to cells types in follicular compact carcinoma were observed, and endothelial cells presented greater RAR $\alpha$ labeling than fibroblasts in compact carcinoma $(P<0.05)$ (Fig. 6A). Similar profile of RXR expression was observed, with stronger labeling in follicular cells than fibroblasts and endothelial cells of healthy glands $(P<0.05)$, whereas RXR expression in both types of carcinomas did not differ according to cell type (Fig. 6B).

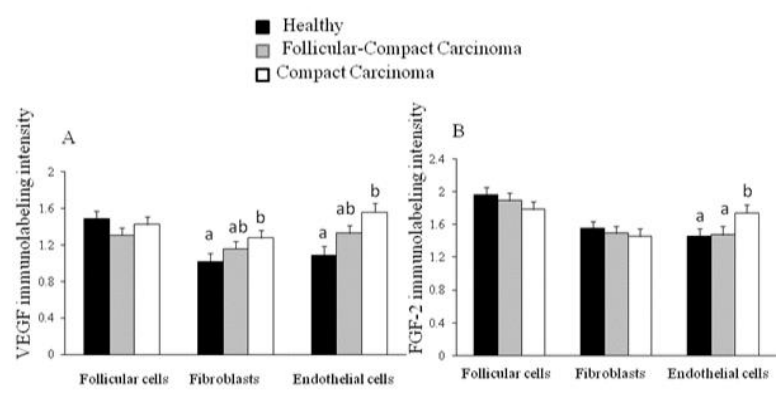

Fig. 5. Immunolabeling intensity of vascular endothelial growth factor (VEGF, A) and fibroblast growth factor-2 (FGF-2, B). Data are expressed as the least square mean \pm pooled S.E.M. Different letters within the same cell type indicate differences, $\mathrm{P}<0.05$.

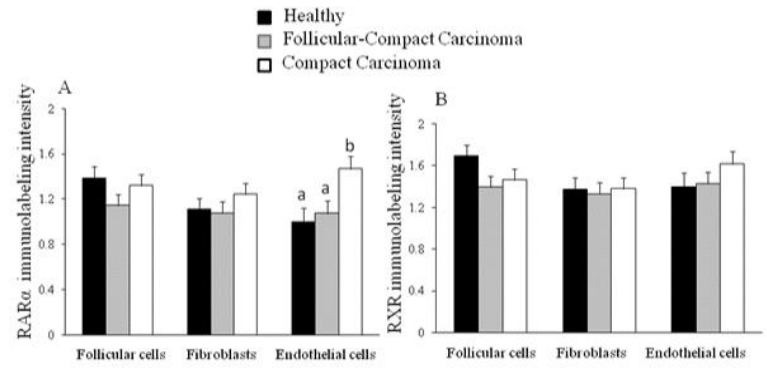

Fig. 6. Immunolabeling intensity of retinoic acid receptor alpha (RAR $\alpha, A)$ and retinoid $X$ receptor (RXR, B). Data are expressed as the least square mean \pm pooled S.E.M. Different letters within the same cell type indicate differences, $\mathrm{P}<0.05$.

\section{Discussion}

Most canine thyroid tumours arise from the follicular epithelium and are classified as follicular, compact or a mixture of the two patterns (follicular-compact) (Barber, 2007). As reported previously (Pessina et al., 2014), cell density and the number of blood vessels were higher in thyroid carcinoma tissues than in healthy glands. Cell density was increased in compact carcinomas when compared to follicular-compact carcinomas, which is consistent with their corresponding histological classification.

To the best of our knowledge, this is the first report showing simultaneous detection of immunoreactive IGF-1/IGF-1R in healthy and carcinomatous thyroid glands in dogs. Cytoplasmic immunoreactivity of both factors was observed in follicular cells, fibroblasts and 
endothelial cells, as reported previously for other cancers in dogs (Buishand et al., 2012; Maniscalco et al., 2014). In carcinomas, a portion of thyroid follicular cells had positive immunolabeling for nuclear IGF-1R, which is consistent with the findings of Sarfstein et al. (2012), who described the translocation of IGF-1R to the nucleus in breast cancer cells and identified a novel mechanism of IGF-1R gene autoregulation. In the present study, IGF-1 and IGF-1R labelling intensity was higher in fibroblasts and endothelial cells of compact carcinoma than in those of healthy thyroid tissues, while follicular-compact carcinoma had intermediate labelling intensity. These findings are consistent with human studies, such as the report by Vella et al. (2001), who showed that IGF-1 and its receptor are overexpressed in thyroid cancer, suggesting that IGF-1R is activated in an autocrine/paracrine manner. The simultaneous increase of IGF-1 and IGF-1R expression in the stroma (fibroblasts and endothelial cells) supports the existence of crosstalk between these cell types; this can lead to the activation of proliferation signals and/or facilitate nutrient access, thus contributing to tumour growth (Bissell and Radisky, 2001; Gribben et al., 2010). These factors were expressed at an intermediate level in follicular-compact carcinomas, which is consistent with the degree of differentiation of this type of tumour compared with compact carcinoma. Indeed, we have recently shown (Castillo et al., 2016) that thyroid follicular compact carcinomas had a greater time to recurrence than compact carcinomas in dogs.

In the present study, we showed that the pattern of expression of VEGF was similar to that of IGF-1/IGF$1 \mathrm{R}$ in the different groups, as demonstrated by the upregulation of VEGF expression in fibroblasts and endothelial cells of compact carcinoma. The upregulation of VEGF in endothelial cells in compact carcinoma when compared to the healthy thyroid tissue was consistent with the findings of our previous study (Pessina et al., 2014). This is in agreement with Campos et al. (2014) that suggested that VEGF may play an important role in the progression of canine thyroid cancer. Our present results showed that FGF-2 expression was higher in endothelial cells of compact carcinoma than in those of healthy glands or follicularcompact glands. These data were consistent with the pattern of VEGF expression in the same cell type, and support the fact that VEGF stimulates endothelial cells to produce FGF-2, which further enhances angiogenesis (Pallares et al., 2006). Overall, data suggest a positive feedback loop between VEGF and FGF-2 that contributes to tumour progression, despite the higher efficacy of the VEGF system for neovascularization compared to FGF-2 as reported previously (Giavazzi et al., 2003). In the present study, no differences in follicular cell expression of IGF-
1/IGF-1R, VEGF and FGF-2 were found among groups, whereas the expression of these factors in stromal cells differed. Tumour progression is promoted by crosstalk between the tumour and its surrounding supporting tissue either via cell-to-cell contact, or mediated by secreted molecules (Bouziges et al., 1991). Indeed, the stroma itself can trigger tumour development (Bissell and Radisky, 2001), and one hypothesis on oncogenesis is based on stromal cell functionality, despite the fact that the mechanisms by which tumour and stromal cells co-evolve remain unclear (Gribben et al., 2010).

The expression of RAR $\alpha$ and RXR in healthy thyroid glands and thyroid carcinomas in dogs has not been reported previously. In humans, the expression of these retinoic receptors in healthy thyroid tissue, thyroid cell lines, and in thyroid adenomas and carcinomas has been reported (Hoftijzer et al., 2009); however, the expression of these receptors in dogs has only been described in lymphoma, melanoma and osteosarcoma (Miyajima et al., 2006; Ohashi et al., 2006; de Mello Souza et al., 2010, 2014)._In the present study, RAR $\alpha$ expression in follicular cells did not differ in carcinomas and healthy thyroid glands. However, endothelial cells of compact carcinomas showed higher expression of RAR $\alpha$ than those of the other groups (healthy and follicular-compact carcinomas), and further studies are needed to help our understanding of the role of this receptor in carcinoma progression. Retinoic receptor expression in thyroid carcinoma is consistent with our recent study (Castillo et al., 2016) in which isotretinoin 9-cis (RA9-cis) treatment increased time of recurrence and survival time in dogs with follicular-compact and compact thyroid carcinoma when compared to doxorubicin after surgery. Miyajima et al. (2006) showed that in canine masts cells, RAR $\alpha$ expression was positively correlated with response to retinoic acid treatment. Because the present study did not test all isoforms of RXR, these data should be considered preliminary. Indeed, Haugen et al. (2004) showed that while RXR $\gamma$ was expressed in different cell lines of thyroid human tumours, it was not expressed in normal thyroid tissue. Moreover, none of the RXR isoforms are expressed in canine nontumoural lymphocytes, whereas RXR $\gamma$ is expressed in $78 \%$ of tumour T cells (de Mello Souza et al., 2014).

In conclusion, factors related to proliferation and angiogenesis were expressed at higher levels in fibroblasts and/or endothelial cells of compact carcinomas than in those of healthy glands, with mostly intermediate expression in follicular-compact carcinomas, suggesting a role of stromal cells in tumour progression.

\section{Acknowledgements}

We gratefully acknowledge the technical assistance of Lic. Claudia Menezes and Rosina Sánchez for 
immunohistochemical evaluation of samples. This work was supported in part by Project No. 277 CSICUdelaR (Uruguay).

\section{Conflict of interest}

The authors declare that there is not conflict of interest.

\section{References}

Barber, L.G. 2007. Thyroid tumors in dogs and cats. Vet. Clin. North Am. Small Anim. Pract. 37(4), 755-773.

Bissell, M.J. and Radisky, D. 2001. Putting tumors in context. Nat. Rev. Cancer 1(1), 46-54.

Boelaert, K., McCabe, C.J., Tannahill, L.A., Gittoes, N.J., Holder, R.L., Watkinson, J.C., Bradwell, A.R., Sheppard, M.C. and Franklyn, J.A. 2003. Pituitary tumor transforming gene and fibroblast growth factor-2 expression: potential prognostic indicators in differentiated thyroid cancer. J. Clin. Endocrinol. Metab. 88(5), 2341-2347.

Boos, A., Meyer, W., Schwarz, R. and Grunert, E. 1996. Immunohistochemical assessment of oestrogen receptor and progesterone receptor distribution in biopsy samples of the bovine endometrium collected throughout the oestrous cycle. Anim. Reprod. Sci. 44, 11-21.

Bouziges, F., Simo, P., Simon-Assmann, P., Haffen, K. and Kedinger, M. 1991. Altered deposition of basement membrane molecule in co-culture of colonic cancer cells and fibroblast. Int. J. Cancer 48(1), 101-108.

Buishand, F.O., van Erp, M.G., Groenveld, H.A., Mol, J.A., Kik, M., Robben, J.H., Kooistra, H.S. and Kirpensteijn, J. 2012. Expression of insulin-like growth factor-1 by canine insulinomas and their metastases. Vet. J. 191(3), 334-340.

Campos, M., Peremans, K., Vandermeulen, E., Duchateau, L., Bosmans, T., Polis, I. and Daminet, S. 2012. Effect of Recombinant Human Thyrotropin on the Uptake of Radioactive Iodine (123I) in Dogs with Thyroid Tumors. PLoS ONE 7(11): e50344. doi:10.1371/journal.pone.0050344.

Campos, M., Ducatelle, R., Kooistra, H.S., Rutteman, G., Duchateau, L., Polis, I. and Daminet, S. 2014. Immunohistochemical expression of potential therapeutic targets in canine thyroid carcinoma. J. Vet. Intern. Med. 28(2), 564-570.

Carmeliet, P. and Jain, R.K. 2000. Angiogenesis in cancer and other diseases. Nature 407, 249-257.

Castillo, V.A., Giacomini, D., Páez-Pereda, M., Stalla, J., Labeur, M., Theodoropoulou, M., Holsboer, F., Grossman, A.B., Stalla, G.K. and Arzt, E. 2006. Retinoic Acid as a Novel Medical Therapy for Cushing's Disease in Dogs. Endocrinology 147(9), 4438-4444.

Castillo, V.A. and Gallelli, M.F. 2010. Corticotroph adenoma in the dog: pathogenesis and new therapeutic possibilities. Res. Vet. Sci. 88(1), 2632.

Castillo, V., Pessina, P., Hall, P., Blatter, M.F., Miceli, D., Arias, E.S. and Vidal, P. 2016. Postsurgical treatment of thyroid carcinoma in dogs with retinoic acid 9 cis improves patient outcome. Open Vet. J. 6(1), 6-14.

Ciampolillo, A., De Tullio, C., Perlino, E. and Maiorano, E. 2007. The IGF-I axis in thyroid carcinoma. Curr. Pharm. Des. 13(7), 729-735.

de Araujo-Filho, V.J., Alves, V.A., de Castro, I.V., Lourenço, S.V., Cernea, C.R., Brandão, L.G. and Ferraz, A.R. 2009. Vascular endothelial growth factor expression in invasive papillary thyroid carcinoma. Thyroid 19(11), 1233-1237.

de Mello Souza, C.H., Valli, V.E., Selting, K.A., Kiupel, M. and Kitchell, B.E. 2010. Immunohistochemical detection of retinoid receptors in tumors from 30 dogs diagnosed with cutaneous lymphoma. J. Vet. Inter. Med. 24(5), 1112-1117.

de Mello Souza, C.H., Valli, V.E. and Kitchell, B.E. 2014. Detection of retinoid receptors in nonneoplastic canine lymph nodes and in lymphoma. Can. Vet. J. 55(1), 1219-1224.

Giavazzi, R., Sennino, B., Coltrini, D., Garofalo, A., Dossi, R., Ronca, R., Tosatti, M.P. and Presta, M. 2003. Distinct role of fibroblast growth factor-2 and vascular endothelial growth factor on tumor growth and angiogenesis. Am. J. Pathol. 162(6), 19131926.

Gribben, J., Rosenwald, A., Gascoyne, R. and Lenz, G. 2010. Targeting the microenvironment. Leuk. Lymphoma 51 Suppl. 1, 34-40. doi: 10.3109/10428194.2010.500072.

Haugen, B.R., Jensen, D.R., Sharma, V., Pulawa, L.K., Hays, W.R., Krezel, W., Chambon, P. and Ecke, R.H. 2004. Retinoid X receptor gamma-deficient mice have increased skeletal muscle lipoprotein lipase activity and less weight gain when fed a highfat diet. Endocrinology 145(8), 3679-3685.

Hoftijzer, H.C., Liu, Y.Y., Morreau, H., van Wezel, T., Pereira, A.M., Corssmit, E.P., Romijn, J.A. and Smit, J.W. 2009. Retinoic acid receptor and retinoid $\mathrm{X}$ receptor subtype expression for the differential diagnosis of thyroid neoplasms. Eur. J. Endocrinol. 160(4), 631-638.

Holmgren, L., O'Reilly, M.S. and Folkman, J. 1995. Dormancy of micrometastases: balance proliferation and apoptosis in the presence of angiogenesis suppression. Nat. Med. 1(2), 149-153.

Jones, J.I. and Clemmons, D.R. 1995. Insulin-like growth factors and their binding proteins: biological actions. Endocr. Rev. 16(1), 3-34.

Kasimanickam, V.R., Kasimanickam, R.K. and Rogers, H.A. 2013. Immunolocalization of retinoic 
acid receptor-alpha, -beta, and -gamma, in bovine and canine sperm. Theriogenology 79(6), 10101018.

Klein, M.K., Powers, B.E., Withrow, S.J., Curtis, C.R., Straw, R.C., Ogilvie, G.K., Dickinson, K.L., Cooper, M.F. and Baier, M. 1995. Treatment of thyroid carcinoma in dogs by surgical resection alone: 20 cases (1981-1989). J. Am. Vet. Med. Assoc. 206(7), 1007-1009.

Kondo, T., Zheng, L., Liu, W., Kurebayashi, J., Asa, S.L. and Ezzat, S. 2007. Epigenetically controlled fibroblast growth factor receptor 2 signaling imposes on the RAS/BRAF/mitogen activated protein kinase pathway to modulate thyroid cancer progression. Cancer Res. 67(11), 5461-5470.

LeRoith, D. and Roberts, C.T. 2003. The insulin-like growth factor system and cancer. Cancer Lett. 195(2), 127-137.

Lin, J.D. and Chao, T.C. 2005. Vascular endothelial growth factor in thyroid cancers. Cancer Biother. Radiopharm. 20(6), 648-661.

Liu, J. and Brown, R.E. 2011. Immunohistochemical expressions of fatty acid synthase and phosphorylated c-Met in thyroid carcinomas of follicular origin. Int. J. Clin. Exp. Pathol. 4(8), 755764.

Liu, Y.J., Qiang, W., Shi, J., Lv, S.Q., Ji, M.J. and Shi, B.Y. 2013. Expression and significance of IGF-1 and IGF-1R in thyroid nodules. Endocrine 44(1), 158-164.

Malaguarnera, R., Morcavallo, A. and Belfiore, A. 2012. The insulin and igf-I pathway in endocrine glands carcinogenesis. J. Oncol. 2012:635614. doi: 10.1155/2012/635614.

Maniscalco, L., Iussich, S., Morello, E., Martano, M., Gattino, F., Miretti, S., Biolatti, B., Accornero, P., Martignani, E., Sánchez-Céspedes, R., Buracco, P. and De Maria, R. 2014. Increased expression of insulin-like growth factor-1 receptor is correlated with worse survival in canine appendicular osteosarcoma. Vet. J. 205(2), 272-280.

Miller, W.H.Jr. 1998. The emerging role of retinoids and retinoic acid metabolism blocking agents in the treatment of cancer. Cancer 83(8), 1471-1482.

Miyajima, N., Watanabe, M., Ohashi, E., Mochizuki, M., Nishimura, R., Ogawa, H., Sugano, S. and Sasaki, N. 2006. Relationship between retinoic acid receptor a gene expression and growth-inhibitory effect of all-trans retinoic acid on canine tumor cells. J. Vet. Intern. Med. 20(2), 348-354.

Nadeau, M. and Kitchell, B.E. 2011. Evaluation of the use of chemotherapy and other prognostic variables for surgically excised canine thyroid carcinoma with and without metastasis. Can. Vet. J. 52(9), 994-998.
Nishida, N., Yano, H., Nishida, T., Kamura, T. and Kojiro, M. 2006. Angiogenesis in Cancer. Vasc. Health Risk Manag. 2(3), 213-219.

Ohashi, M., Miyajima, N., Nakagawa, T., Takahashi, T., Kagechika, H., Mochizuki, M., Nishimura, R. and Sasaki, N. 2006. Retinoids induce growth inhibition and apoptosis in mast cell tumor cell lines. J. Vet. Med. Sci. 68(8), 797-802.

Pallares, J., Rojo, F., Iriarte, J., Morote, J., Armadans, L.I. and de Torres, I. 2006. Study of microvessel density and the expression of the angiogenic factors VEGF, bFGF and the receptors Flt-1 and FLK-1 in benign, premalignant and malignant prostate tissues. Histol. Histopathol. 21(8), 857-865.

Patnaik, A.K. and Lieberman, P.H. 1991. Gross, histologic, cytochemical, and immunocytochemical study of medullary thyroid carcinoma in sixteen dogs. Vet. Pathol. 28(3), 223-233.

Pessina, P., Castillo, V., Sartore, I., Borrego, J. and Meikle, A. 2014. Semiquantitative immunohistochemical marker staining and localization in canine thyroid carcinoma and normal thyroid gland. Vet. Comp. Oncol. 14(3), e102-12. doi: 10.1111/vco.12111.

Ramos-Vara, J.A., Miller, M.A., Johnson, G.C. and Pace, L.W. 2002. Immunohistochemical detection of thyroid transcription factor-1, thyroglobulin, and calcitonin in canine normal, hyperplastic, and neoplastic thyroid gland. Vet. Pathol. 39(4), 480487.

Redler, A., Di Rocco, G., Giannotti, D., Frezzotti, F., Bernieri, M.G., Ceccarelli, S., D'Amici, S., Vescarelli, E., Mitterhofer, A.P., Angeloni, A. and Marchese, C. 2013. Fibroblast growth factor receptor-2 expression in thyroid tumor progression: potential diagnostic application. PLoS One. 8(8), e72224. doi: 10.1371/journal.pone.0072224.

Restucci, B., Maiolino, P., Paciello, O., Martano, M., De Vico, G. and Papparella, S. 2003. Evaluation of angiogenesis in canine seminomas by quantitative immunohistochemistry. J. Comp. Pathol. 128(4), 252-259.

Sarfstein, R., Pasmanik-Chor, M., Yeheskel, A., Edry, L., Shomron, N., Warman, N., Wertheimer, E., Maor, S., Shochat, L. and Werner, H. 2012. Insulinlike growth factor-I receptor (IGF-IR) translocates to nucleus and autoregulates IGF-IR gene expression in breast cancer cells. J. Biol. Chem. 287(4), 2766-2776.

Tlsty, T.D. and Coussens, L.M. 2006. Tumor stroma and regulation of cancer development. Annu. Rev. Pathol. 1, 119-150.

Vella, V., Sciacca, L., Pandini, G., Mineo, R., Squatrito, S., Vigneri, R. and Belfiore, A. 2001. The IGF system in thyroid cancer: new concepts. Mol. Pathol. 54(3), 121-124. 
White, S.D., Rosychuk, R.A., Scott, K.V., Trettien, A.L., Jonas, L. and Denerolle, P. 1993. Use of isotretinoin and etretinate for the treatment of benign cutaneous neoplasia and cutaneous lymphoma in dogs. J. Am. Vet. Med. Assoc. 202(3),
387-391.

Wucherer, K.L. and Wilke, V. 2010. Thyroid cancer in dogs: An update based on 638 cases (19952005). J. Am. Anim. Hosp. Assoc. 46(4), 249254. 